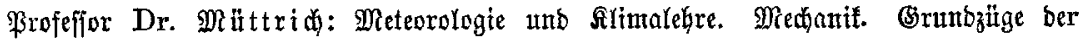
Differential= unb Sntegralredinung.

(5eh. Regierungsrat ßrofeffor Dr. Remelé: argeneine uno anorganifde Ehentie.

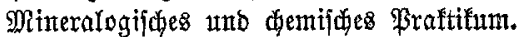

Frofeffor Dr. $\Re$ aman $\mathfrak{n}$ : Stontiortzlehre.

Frofefior Dr. $ఠ$ dimar

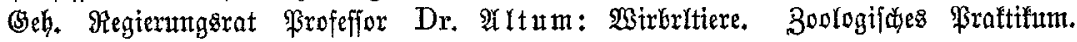
3oologitide erpturitionten.

Frivatbozent Dr. E⿺ffetn: Fif fizudut.

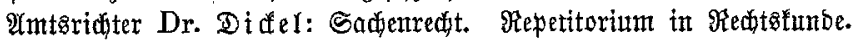

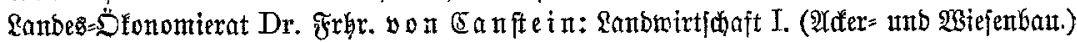

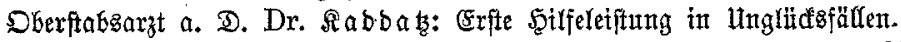

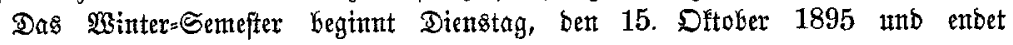
Somnabend, ben 21. Miärz 1896.

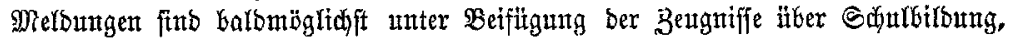

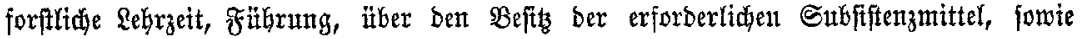

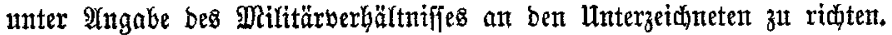

Der Direftor ber Forft=-2ifabemie. Da n of er $\mathfrak{m} \mathfrak{a} \mathfrak{n}$.

\title{
forftzzlfadentie Zrïnden.
}

Beginn De Winterfentefter Dienstag, Den 15, Dltober 1895.

Sdyluñ 14. Tage yor Sftern 1896.

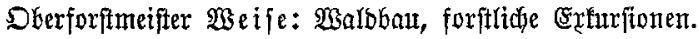

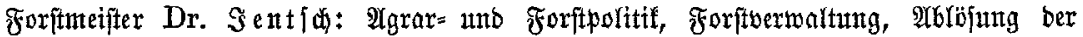
(Srunbgeredittgfeiten, forftride Extitritonet.

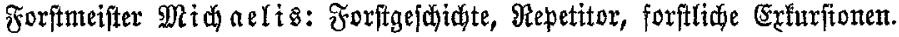

Forftmeifter Selrbeim: Forftbenubung, Repetitor, forftlide Erfurftonen.

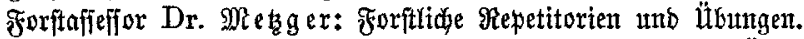

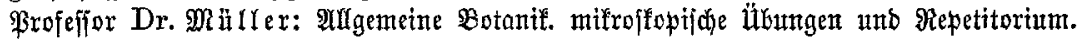
(seh. Regterungerat Profejior Dr. Me Forfifaffeffor Dr. Milani: 3oologifdes Repetitorium.

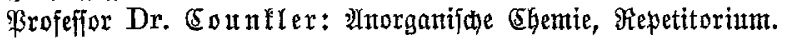

Brofeffor Dr. Fontuberger: Meteorologie.

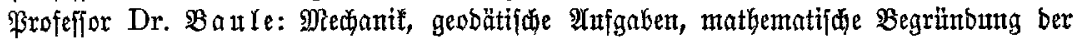

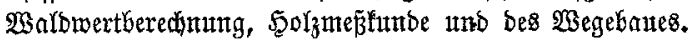

(Seh. Suftizrat Frofeffor Dr. 3iebarth: Eivilredt II.

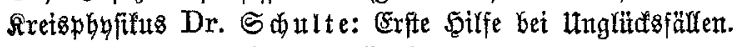

Dr. Es ler: Sanbwirtidiaft fïr Forftleute.

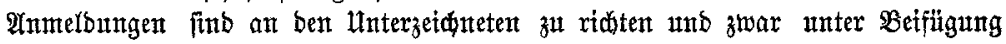

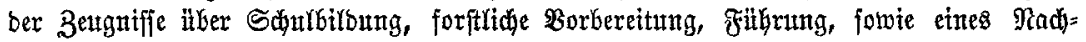

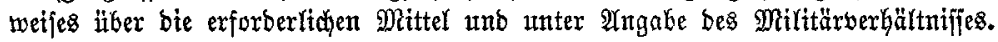

Der Direftor ber Forft $=2$ Afabemic. $\mathfrak{B} \mathfrak{e} \mathfrak{i}\{\mathfrak{e}$. 